УДК $541.1+628.16$

\title{
Математическое моделирование и расчет процесса деминерализации воды в промышленном фильтре Сообщение 3. Влияние стадии взрыхления катионита на процесс регенерации и последующей очистки
}

\author{
Комарова И.В., Галкина Н.К., Прудковский А.Г. \\ Институт геохимии и аналитической химии им. В.И.Вернадского РАН, Москва
}

Поступила в редакцию 25.12.2016 г.

Получены экспериментальные данные по распределению катионов очищаемой воды по слою катионита КУ-2 до и после его взрыхления путем отбора проб на разной высоте работающего ионообменного фильтра. По программе «Createscheme» рассчитаны распределения, которые хорошо совпадают с экспериментальными данными. Показано, что, при взрыхлении происходит полное перемешивание слоя катионита независимо от скорости подачи взрыхляющей воды в исследованном диапазоне скоростей потока.

Ключевые слова: взрыхление, отбор проб катионита, расчет, распределение катионов, выходные кривые.

\section{Mathematical simulation and calculation of the process of water demineralization in industrial filter Part 3. Influence of the cation-exchanger backwashing stage on regeneration and following water purification processes}

\author{
Komarova I.V., Galkina N.K., Prudkovskii A.G. \\ Vernadsky Institute of Geochemistry and Analytical Chemistry of Russian Academy of Sciences \\ (GEOKHI RAS), Moscow
}

The aim of the work was to study the influence of the intensity of bed backwashing on water purification process.

Experiments were carried out at the Novocherkassk Power Plant central desalting unit, on an industrial filter loaded with the fresh cationic resin KU-2 in hydrogen form. Backwashing the filter before regeneration was carried out in several successive working cycles at different flow rates. For analysis of the sorbent on sodium, magnesium, calcium and hydrogen content, the samples of cationic resin was taken at several points along the column bed before and after backwashing by the use of special sampler. Experimental distribution of cations in the resin bed was compared to the calculated data obtained with the use of the «CREATESCHEME» program under the assumption of complete mixing of a sorbent bed.

Good agreement between experimental data and the results of calculations for industrial scale process approves the validity of model premises including the fact of full mixing the resin bed at backwashing stage, independently on the flow rate of washing water in the range of used conditions.

Keywords: backwashing, cationic resin sampling, calculation, component distribution, breakthrough curves. 


\section{Введение}

Целью настоящей работы являлось изучение технологических особенностей работы промышленного фильтра. В предыдущих сообщениях была рассмотрена гидродинамика стадий регенерации и отмывки катионита, а также влияние изменения входных параметров на процесс очистки воды на катионитовом фильтре первой ступени центральной обессоливающей установки Новочеркасской ГРЭС.

Особого внимания при эксплуатации промышленных фильтров заслуживает стадия взрыхления, необходимость которой вызвана нарастанием перепада давления на слое ионита, которое вызывается кольматацией порового пространства мелкими фракциями ионита. Рост перепада давления происходит кроме того в результате слеживания слоя ионита за счет гидродинамического воздействия потока воды во время рабочего цикла.

Взрыхление ионита устраняет эти нежелательные явления, однако приводит к перемешиванию ионита, что изменяет распределение компонентов по высоте слоя ионита, которое является исходным для расчета последующей стадии [1]. В данном сообщении приведены результаты влияния взрыхления на процесс очистки воды.

Для описания процесса перемешивания ионита ранее нами было предложена диффузионная математическая модель взрыхления и определен эффективный коэффициент диффузии (коэффициент перемешивания) на лабораторной установке [2]. Это позволяет рассчитывать распределение по слою ионита при известном распределении компонентов по слою ионита до взрыхления и известном коэффициенте перемешивания.

Расчетная часть работы выполнялась по программе «Createscheme» [3], реализующей все особенности промышленного процесса. Программа позволяет проводить расчёты технологических циклов, состоящих из стадий сорбции, взрыхления, регенерации и отмывки на многоколоночной системе фильтров в многокомпонентных системах при переменных условиях на входе.

\section{Эксперимент}

Для изучения влияния взрыхления на процесс получения очищенной воды заданного качества были проведены четыре серии опытов при различных условиях взрыхления слоя катионита. Одна серия опытов проводилась без взрыхления, остальные с взрыхлением при скоростях потока 35,70, $105 \mathrm{~m}^{3} /$ час.

Экспериментальное определение степени перемешивания в промышленных условиях было выполнено путем отбора проб катионита пробоотборником до и после взрыхления. Для этой цели был использован пробоотборник-щуп, позволяющий однократно с разной высоты слоя отобрать пробу сорбента. Таким способом были отобраны пробы сорбента до и после взрыхления в одном из опытов каждой серии.

\section{Обсуждение результатов}

На рис. 1 представлено расчетное распределение компонентов по слою катионита после рабочего цикла в сравнении с экспериментальными данными, полученными при отборе проб на разной высоте слоя. Это распределение получено в результате рабочего цикла на частично регенерированном катионите КУ-2. Степень регенерации составляла 0.25 . Поэтому в отличие от распределения катионов по слою катионита в водородной форме в замыкающих слоях катионита присутствует определенное количество двухзарядных ионов магния и кальция, оставшихся в фильтре

Комарова и др. / Сорбционные и хроматографические процессы. 2017. Т. 17. № 1 
после предшествующей регенерации. Показано хорошее совпадение расчетного распределения после рабочего цикла с экспериментальным, полученным на основе анализа проб сорбента, вынутых из фильтра после рабочего цикла. На рис. 2 представлено экспериментальное распределение компонентов по слою, полученное на основе анализа отобранных проб после взрыхления со скоростью $70 \mathrm{~m}^{3} /$ час в течение 30 минут, в соответствии с технологическим регламентом и рассчитанное распределение при предположении полного перемешивания слоя.

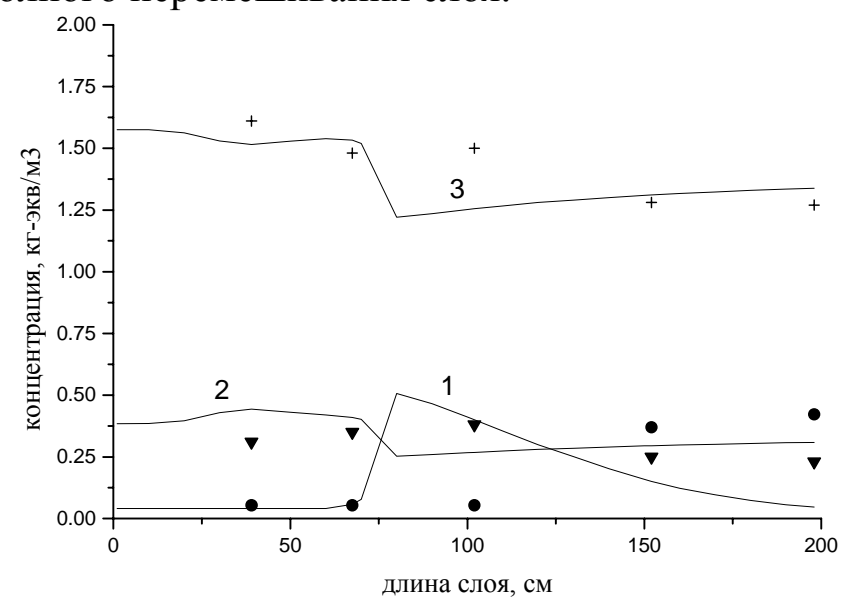

Рис. 1. Расчетное и определенное пробоотборником распределение ионов по слою катионита после рабочего цикла: 1 - натрий 2 - магний 3 - кальций

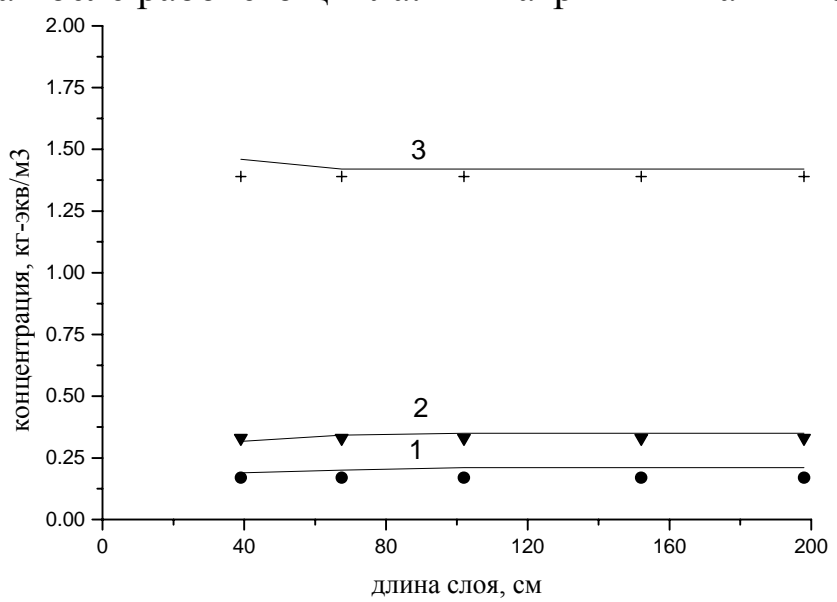

Рис. 2. Расчетное и определенное пробоотборником распределение ионов после взрыхления со скоростью 70 м³/час: 1 - натрий 2 - магний 3 - кальций

Оценка степени перемешивания выполнена также на основании сопоставления выходных кривых регенерации, полученных в середине слоя и на выходе из фильтра. На рис.3 представлены экспериментальные выходные кривые регенерации натрия в середине слоя и на выходе из фильтра после взрыхления с разными скоростями. Положение пика натрия в середине слоя и на выходе одинаково, что косвенно подтверждает полное перемешивание при взрыхлении.

Из представленных данных следует, что процесс взрыхления в изученном диапазоне скоростей потока не зависит от скорости подачи взрыхляющей воды и обеспечивает полное перемешивание компонентов по слою катионита.

На рис.4 представлены экспериментальные выходные кривые натрия на выходе из фильтра при очистке на частично регенерированном катионите (степень регенерации 0.25) со взрыхлением и без взрыхления. Из рисунка ясно, почему при 
одинаковых условиях регенерации качество воды, полученное на фильтре, который работает без взрыхления, лучше, чем после взрыхления.

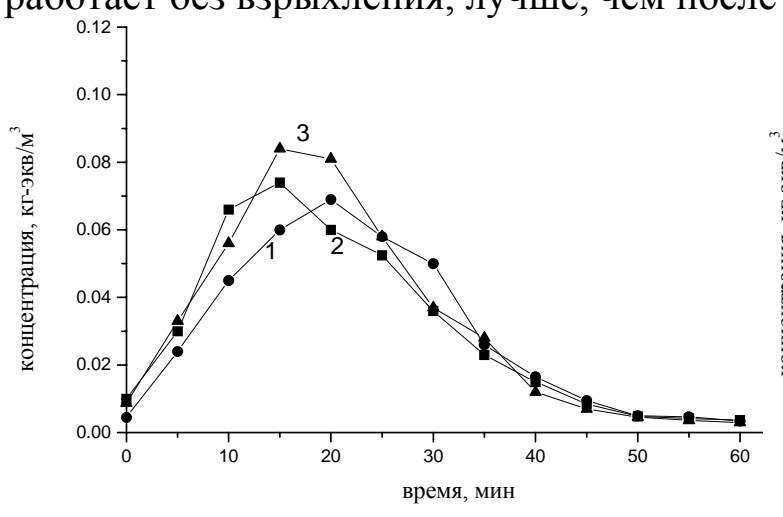

a

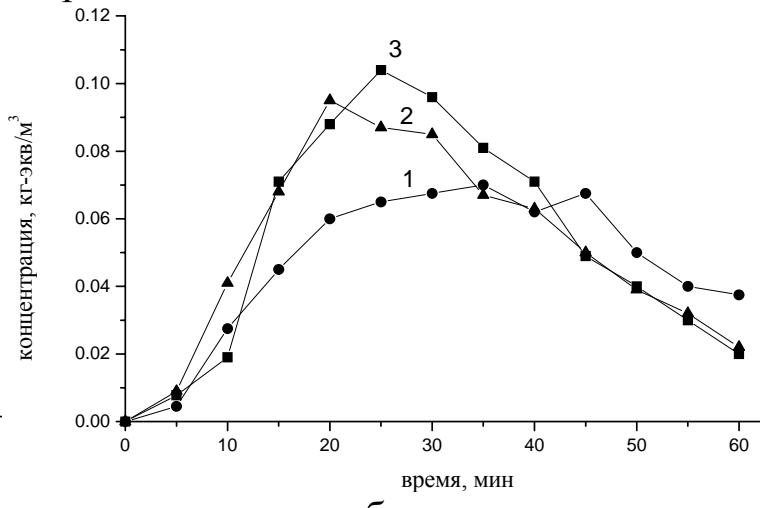

6

Рис. 3. Экспериментальные выходные кривые иона натрия при регенерации катионита в середине слоя -(а) и на выходе из фильтра - (б) после взрыхления катионита с разными скоростями потока: $1-35 \mathrm{~m}^{3} /$ час, $2-70 \mathrm{~m}^{3} / \mathrm{чаc,} 3-105 \mathrm{~m}^{3} /$ час

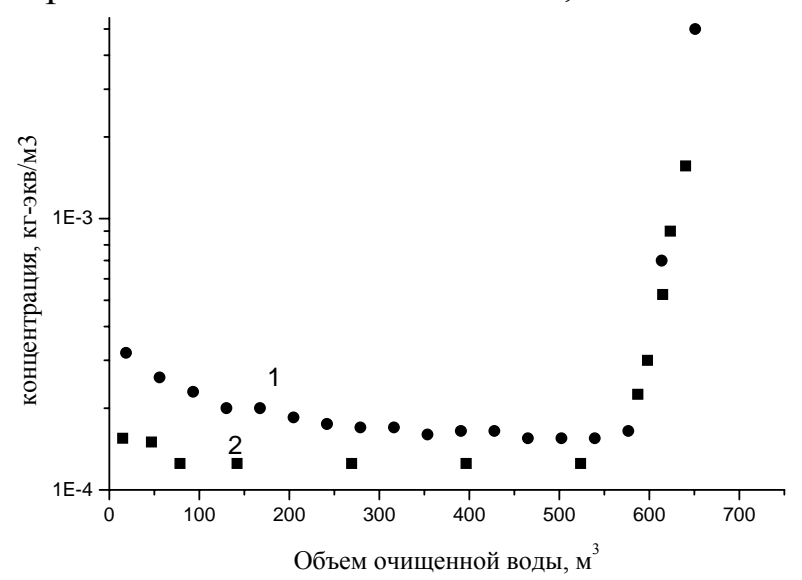

Рис. 4. Экспериментальные выходные кривые натрия при очистке на частично регенерированном катионите: 1 - взрыхление со скоростью $70 \mathrm{~m}^{3} /$ час, 2 - без взрыхления

\section{Заключение}

Необходимость взрыхления промышленного фильтра обусловлена нарастанием перепада давления на слое ионита после рабочего цикла. В то же время взрыхление приводит к изменению характера распределения компонентов по слою катионита, что негативно влияет на результат регенерации. Для получения очищенной воды заданного качества после взрыхления требуется больший расход реагента, так как наименее сорбируемый ион натрия оказывается в результате взрыхления равномерно распределенным по всему слою, а не находится в нижних слоях фильтра. Для экономии реагента можно рекомендовать регулярное взрыхление только верхней части слоя, а через 10-20 циклов взрыхление всего слоя ионита.

По программе «Createscheme» рассчитаны распределения, которые хорошо совпадают с экспериментальными данными. Показано, что при взрыхлении происходит полное перемешивание слоя катионита независимо от скорости подачи взрыхляющей воды в исследованном диапазоне скоростей потока. 


\section{Список литературы}

1. Аргин М.А., Комарова И.В., Закова И.М., Алексеева Л.М. и др. Атомная энергия.. 1985. Т. 59. С.135-137

2. Закова И.М., Комарова И.В., Одинцов К.Ю. Теория и практика сорбционных проиессов. 1980. № 13. С. 30-32

\section{References}

1. Argin M.A., Komarova I.V., Zakova I.M., Alekseeva L.M et al., Atomnaja jenergija, 1985, Vol. 59, pp.135-137.

2. Zakova I.M., Komarova I.V., Odincov K.Ju., Teorija i praktika sorbcionnyh processov, 1980, Vol. 13, pp. 30-32.

Комарова Ирина Владимировна к.х.н., старший научный сотрудник, лаборатория сорбционных методов, ГЕОХИ РАН

Галкина Надежда Константиновна - к.х.н., старший научный сотрудник, лаборатория сорбционных методов, ГЕОХИ РАН

Прудковский Андрей Гаральдович - д.ф-м.н., старший научный сотрудник, лаборатория сорбционных методов, ГЕОХИ РАН,
3. Прудковский А.Г., Комарова И.В., Галкина Н.К. Сорбционные и хроматографические прочессы. 2014. Т. 14. № 5. С.824-831

3. Prudkovskii A.G., Komarova I.V., Galkina N.K., Sorbtsionnye i khromatograficheskie protsessy, 2014, Vol. 14, No 5, pp. 824-831.

Komarova Irina V. - Ph.D. (Chem.), Senior researcher, Lab of Sorption Methods, GEOKHI RAS

Galkina Nadezda K. - Ph.D. (Chem.), Senior researcher, Lab. of Sorption Methods, GEOKHI RAS

Prudkovskii Andrei G. - Dr.Sci.

(Phys/Math.), Leading researcher, Lab of Sorption Methods, GEOKHI RAS 